DIW BERLIN

Discussion Papers

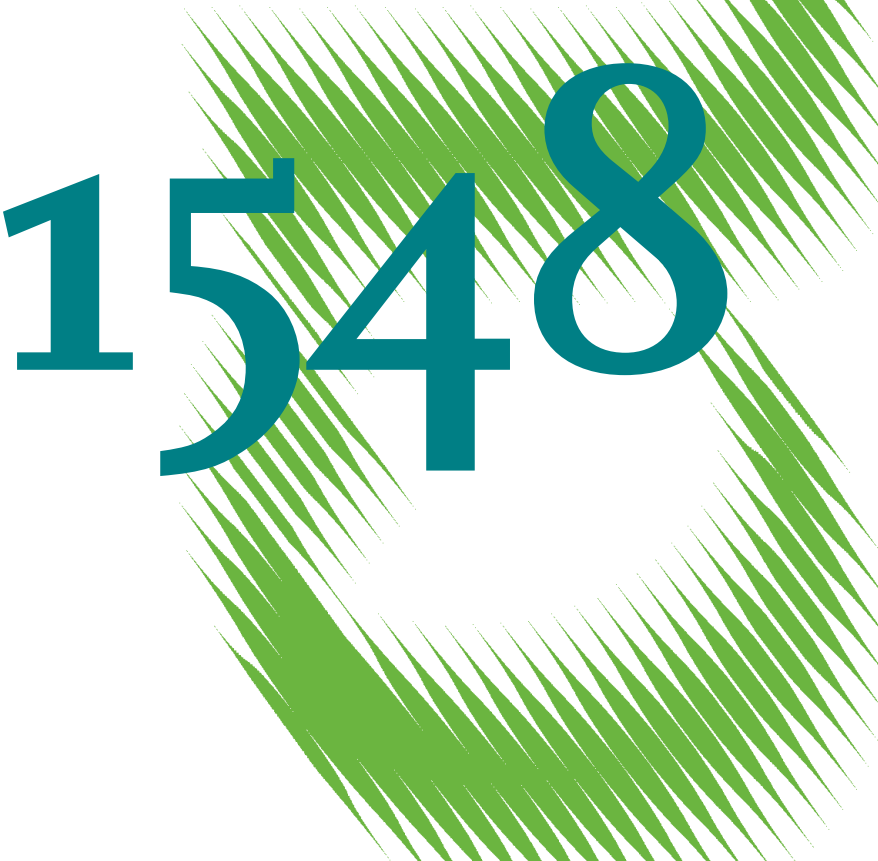

Lifting the US Crude Oil Export Ban: A Numerical Partial-Equilibrium Analysis 
Opinions expressed in this paper are those of the author(s) and do not necessarily reflect views of the institute.

IMPRESSUM

(C) DIW Berlin, 2016

DIW Berlin

German Institute for Economic Research

Mohrenstr. 58

10117 Berlin

Tel. +49 (30) $89789-0$

Fax +49 (30) $89789-200$

http://www.diw.de

ISSN electronic edition 1619-4535

Papers can be downloaded free of charge from the DIW Berlin website:

http://www.diw.de/discussionpapers

Discussion Papers of DIW Berlin are indexed in RePEc and SSRN:

http://ideas.repec.org/s/diw/diwwpp.html

http://www.ssrn.com/link/DIW-Berlin-German-Inst-Econ-Res.html 


\title{
Lifting the US crude oil export ban: A numerical partial-equilibrium analysis
}

\author{
Lissy Langer $^{\mathrm{a}, \mathrm{b}}$, Daniel Huppmann ${ }^{\mathrm{c}, \mathrm{d}, \mathrm{a}}$, Franziska Holz ${ }^{\mathrm{a}, \mathrm{e}}$ \\ lissy.langer@tu-berlin.de, huppmann@iiasa.ac.at, fholz@diw.de
}

February 6, 2016

The upheaval in global crude oil markets and the boom in oil production from shale plays in North America have brought scrutiny on the export ban for crude oil in the United States. This paper examines the global flows and strategic refinery adjustments in a spatial, game-theoretic partial-equilibrium model. We consider detailed supply chain infrastructure with multiple crude oil qualities (supply), distinct oil products (demand), as well as specific refinery configurations and modes of transport (mid-stream). Investments in production capacity and infrastructure are endogenous. We compare two development pathways for the global oil market: one projection retaining the US export ban, and a counterfactual scenario lifting the export restrictions.

Lifting the US crude ban, we find significant expansion of US sweet crude exports. In the US refinery sector, more heavy sour crude is imported and transformed. While US producers gain, the profits of US refiners decrease, due to reduced market distortions and a more efficient resource allocation. Countries importing US sweet crude benefit from higher product output, while avoiding costly refinery investments. Producers of heavy sour crude (e.g. the Middle East) are incentivised to climb up the value chain to defend their market share and maintain their dominant position.

Keywords: energy system model, crude oil market, US crude export ban, refining capacity, infrastructure investment

JEL Codes: Q41, Q47, Q48, C61

a German Institute for Economic Research (DIW Berlin) Mohrenstr. 58, 10117 Berlin, Germany

b Chair for Operations Management, Technische Universität Berlin ST1-1, Steinplatz 2, 10623 Berlin, Germany

c Department of Civil Engineering \& Systems Institute, Johns Hopkins University 3400 N. Charles St., Baltimore, MD 21218, USA

d International Institute for Applied Systems Analysis (IIASA) Schlossplatz 1, 2361 Laxenburg, Austria

e Hertie School of Governance Friedrichstr. 180, 10117 Berlin, Germany 


\section{Introduction}

As a response to the first oil crisis, in 1975 the United States introduced restrictions on the export of domestically produced crude oil. The objective at the time was to insulate the US energy market from global price volatilities and strategic price-setting by the Organization of Petroleum Exporting Countries (OPEC). In 2013, nevertheless, the US still imported about $50 \%$ of their refinery input (Kilian, 2015). Because demand for oil products exceeds domestic production in spite of the shale oil revolution, consumers and industry in the US remain vulnerable and exposed to global price shocks (Brown and Huntington, 2015, Grossman, 2013). Also, the profitability of the United States shale oil expansion depends on global crude prices (API, 2014, Aguilera, 2014, Aguilera et al. 2009). Despite the export ban, minor quantities are already being exported; in the first quarter of 2015 , about $5 \%$ of domestic crude oil was exported due to regulatory exceptions and waivers implemented in recent years according to the Energy Information Administration (EIA, 2015a).

We introduce the structure of the United States crude oil market in a global framework and examine the effects of lifting the crude oil export restrictions. In doing so, we consider production levels, strategic investments and crack spread. The crack spread as the price differential between crude oil and the refined product, along with the costs of transformation and the product yields, determines the profit margins of the US refiners. In addition, the imports and exports of the United States, their magnitude and quality, as well relevant shifts in the global trade patterns are analyzed. Medlock (2015) provides an overview of recent publications on lifting the US crude oil export ban. Our paper adds to the literature by being the first combining a detailed, disaggregated supply chain model of the global crude oil market, while endogenously including investments and adaptations by key producers and consumers across the world. Thereby in our model analysis, we are able to determine the consequences of a US policy shift on the global oil market from an upstream, midstream and downstream perspective. This paper focuses on the induced changes of the midstream players, especially refinery capacities and investments, as well as the shifts of global crude oil and oil product flows. In addition to that, we outline the adjustments of the US oil market in greater detail.

\section{The United States crude oil market}

The distinction between different crude oil qualities is key to comprehending the strategic adaptations of the oil sector. Because the crude oil quality affects the product output, the refineries adapt their technical configuration to match the available crude oil. Many economists think of the crude oil market in terms of a bathtub model (e.g., Huppmann, 2013), with crude being a perfectly homogeneous good and transport costs to be negligible. Different types of crude oil are usually converted into a standard "barrel of oil equivalent (boe)" by thermal equivalence, but this neglects the variations in economic value between different types of crude oil and associated gas (Smith, 2015). The reality from an engineering perspective is far more complicated.While many economists think of the crude oil market in terms of a bathtub model with crude being a perfectly homogeneous good and transport costs to be negligible, the reality from an engineering perspective is far more complicated. Refinery investments not only reflect the available crude oil, but also the most desired products in the given region; in addition we observe a significant lock-in effect since modifications of a refinery configuration or transformation infrastructure are costly and time-consuming. 


\subsection{Available crude oil supply - the refinery slate}

In general, every crude oil has specific characteristics. There is no universal approach to aggregate crude oils, consequently the categories and thresholds differ across sources. For detailed information on the United States production slate (i.e. crude oil mix) and the aggregation used by the EIA, see EIA (2015b). In addition, the yearly published "World Oil and Gas Review" by ENI (2014) gives a good overview on the available global crude oil qualities and their production shares. One simplified but common way is to distinguish between light and heavy crude (by API gravity) on the one hand, and sweet and sour crude (by sulfur content) on the other hand (see for example Hackett et al. 2013, Avis and Birch 2009, Abella and Bergerson 2012a).

Sweet crude oils, with a lower sulfur content than sour crude oils (see Figure 1), do not need further handling to fulfill sulfur emission requirements. Most sweet crude oils, for example the Brent basket or the West Texas Intermediate (WTI), are also light crude oils. For this reason, we aggregate these two properties to the crude oil category light sweet crude, in the following called sweet crude (indicated in the lower section in Figure 1). This category made up about $35 \%$ of the global production output in 2010, which we use as base year in the numerical partial-equilibrium model. The properties of sweet crude oil are already close to the most desired and valuable products: transportation and heating fuels. Therefore, sweet crude can be transformed in a conventional refinery and does not need advanced technical equipment such as coking or hydrocracking units; we will discuss the engineering aspects of refining in more detail later on.

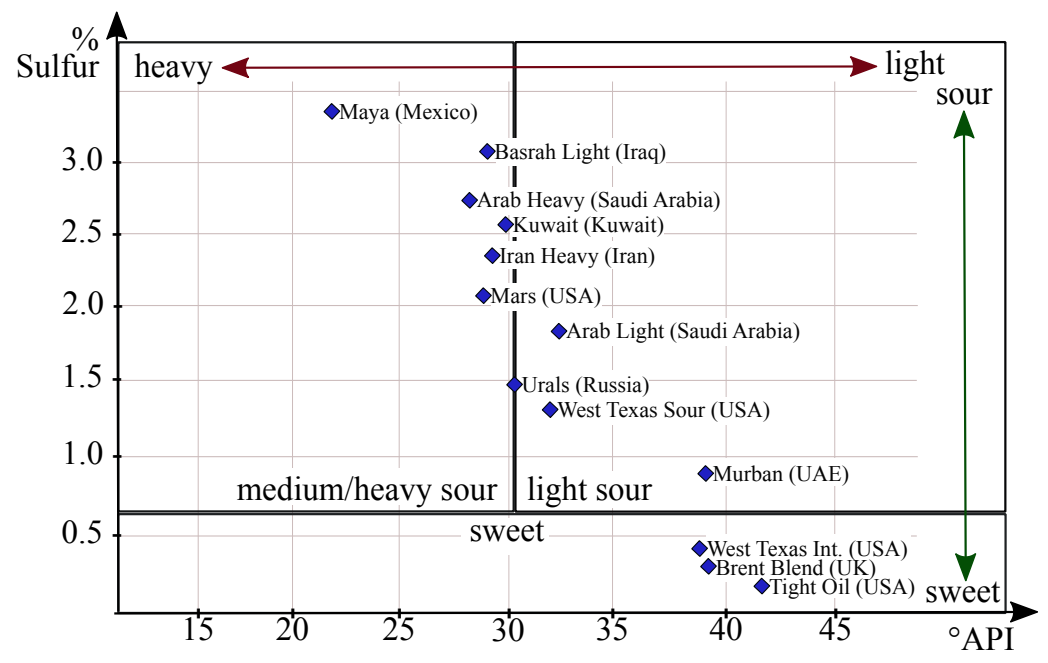

Figure 1: Assigned categories of oil qualities and some benchmark crude oils

Furthermore, crude oils can be further differentiated in light, medium and heavy crude oils based on their API gravity (see Figure 1). As mentioned earlier sweet crude oils mostly are light crude oils with an API gravity higher than 31. Our model differentiates between two sour crude oil qualities: light sour crude, with an API gravity above 31, and medium/heavy sour crude, with an API gravity lower 31 (referred to as heavy crude oil in the following). Light sour crude, however, only made up $9 \%$ of the global production in 2010 and in the United States light sour crude oils play an even smaller role. Heavy crude oil needs advanced refineries, mostly providing large additions of hydrogen, to produce high-demand products. Yet, it still yields a lower share of valuable products than sweet crude (API, 2014, Abella and Bergerson, 2012a). That is why heavy crude oils trade at a discount of $20-50 \%$ compared to e.g. the sweet WTI 
benchmark (Kilian, 2015). See Table 1 for an overview of the refinery yields of the different input crude oils in the given refinery configurations. These will be explained in greater detail later on.

\begin{tabular}{|l||l|c|c|c|c|}
\hline & crude oil quality & LPG & Gasoline & Diesel & Fuel Oil \\
\hline \hline \multirow{2}{*}{$\begin{array}{l}\text { Hydro- } \\
\text { skimming }\end{array}$} & Sweet & 0.03 & 0.24 & 0.49 & 0.24 \\
\cline { 2 - 6 } & Light sour & 0.04 & 0.16 & 0.38 & 0.42 \\
\cline { 2 - 6 } & Medium/heavy sour & 0.05 & 0.16 & 0.35 & 0.44 \\
\hline \hline \multirow{2}{*}{$\begin{array}{l}\text { Catalytic } \\
\text { Cracking }\end{array}$} & Sweet & 0.04 & 0.54 & 0.35 & 0.07 \\
\cline { 2 - 6 } & Light sour & 0.06 & 0.48 & 0.28 & 0.18 \\
\cline { 2 - 6 } & Medium/heavy sour & 0.06 & 0.42 & 0.19 & 0.33 \\
\hline \hline \multirow{2}{*}{$\begin{array}{l}\text { Hydro- } \\
\text { cracking }\end{array}$} & Sweet & 0.04 & 0.32 & 0.63 & 0.01 \\
\cline { 2 - 6 } & Light sour & 0.06 & 0.18 & 0.60 & 0.16 \\
\cline { 2 - 6 } & Medium/heavy sour & 0.04 & 0.26 & 0.54 & 0.16 \\
\hline \hline \multirow{2}{*}{ Coking } & Sweet & 0.05 & 0.56 & 0.37 & 0.02 \\
\cline { 2 - 6 } & Light sour & 0.11 & 0.53 & 0.38 & 0.03 \\
\cline { 2 - 6 } & Medium/heavy sour & 0.07 & 0.51 & 0.38 & 0.04 \\
\hline
\end{tabular}

Table 1: Overview of the volume $\%$ yield of the given refinery configurations

The United States refinery sector has been investing in advanced refinery technology, since the majority of the remaining crude oil reserves is heavy crude and not sweet crude. Shale oil reserves may change that picture, but are still hard to quantify at this point in time. The dramatic drop in crude oil prices over the years 2014/2015 also calls into question the long-term economic viability of shale oil exploration and production.

In 2010, $61 \%$ of the United States refining capacity was made up of advanced technologies, in comparison to only $33 \%$ globally according to the Oil \& Gas Journal (2010). With the increasing unconventional oil production after 2003, additional sweet crude from the United States and heavy crude from Canada has entered the US market. Even though the refining process of shale oils still holds challenges (Benoit and Zurlo, 2014), the economics of shale drive market adjustments towards this new supply source (Kilian, 2015). Verleger Jr. (2015) goes even further and argues that the price spike of 2008 was driven to a large extent by new regulation requiring a shift to low-sulfur diesel in Europe. Global refining capacity did not match available crude oil production capacity to satisfy that demand, upending the prevailing market balance and turning the price path into a rollercoaster. However, the shale oil boom also changed the regional patterns of the crude oil sector in the US, and infrastructure bottlenecks currently impede the switch to a more efficient allocation of crude oil types to the refineries best equipped to handle them. The lack of pipeline infrastructure has led to a surge in crude oil being transported by rail, despite the numerous public health and safety concerns (Oke et al. 2016).

\subsection{United States refinery and transportation infrastructure}

Most refineries on the United States Gulf Coast, in Texas and the Midwest have been technically retrofitted to meet the supply of predominantly heavy crude in that region. Conventional (simple) refineries on the East Coast are mostly used to transform sweet crude, to a considerable part imported from the Middle East and Africa. Though they could also be used to transform both sweet and heavy crude oil, they would yield a high share of low-value fuel oil when transforming heavy crude (see Table 1). To refine 
this crude oil quality at economically viable profit margins, advanced refineries are needed (API, 2014).

In recent years, the United States West Texas Intermediate (WTI) benchmark index traded at a lower price than the European Brent basket, even though both are comparable sweet crude oil qualities. The United States oil had to be sold at a discount or stored, because the main oil hub at Cushing, OK was receiving sweet crude from the Midwest shale oil fields and heavy crude from the Canadian oil sands, but had no suitable outlet due to infrastructure bottlenecks. There are no pipelines to transport the sweet crude to the conventional refineries on the East Coast, while barges and rail cars were not able to handle the quantities in question. In addition, security concerns have been raised after more crude oil was transported by rail, resulting in critical incidents. When a pipeline to Texas was built in 2010, that only helped draining off the heavy crude because of the vast retrofitting of the refineries in that region. Reversing, extending and building pipelines is expensive and time-consuming. Diversifying the input crude of refineries often turns out to be unprofitable due to the high degree of specialization (Platts, 2013).

The regionally insulated shale oil supply, detached from the global oil market through both infrastructure constraints and the export ban, results in lower market prices for domestic crude oil in the United States and explains the price gap between WTI and Brent in recent years. These lower prices, however, do not reach customers, but yield extra rents to the refinery sector in the United States (Borenstein et al., 2014). They gain from cheap high-yield supply, selling the output products, via a pipeline network specifically in place for oil products and no export ban, at global market prices. This way, refineries have a major incentive to prevent lifting the crude export ban. In addition, necessary investments in refineries and transportation infrastructure are hindered by skepticism regarding the prospect of shale oil due to geological and engineering risks, as well as political and regulatory uncertainties about the crude ban itself (Kilian 2015) as well as the recent price drop of crude oil. A similar story was unfolding in the US natural gas sector (Richter, 2015).

\section{The partial-equilibrium global energy market model}

For the scenarios, we developed a spatial partial-equilibrium model, incorporating the essential aspects of the global oil and refinery market. We start with the base year 2010 and forecast the oil market for 2020 and 2030 under the given scenario assumptions of lifting or retaining the US crude oil export ban. The problem is formulated as a Generalized Nash Equilibrium (GNE) between non-cooperative players and solved as a Mixed Complementarity Problem (MCP). This way game-theoretic aspects such as induced market power can be analyzed. The mathematical formulation is based on the partial-equilibrium energy market model MultiMod, developed by DIW Berlin and NTNU Trondheim (Huppmann and Egging, 2014). The formulation is implemented in the General Algebraic Modeling System (GAMS) and solved with the PATH solver (Ferris and Munson, 2000).

The supply of crude and demand for oil products is represented by 30 global nodes, each containing crude suppliers differentiated by oil type, service providers depicting the refining sector and transportation infrastructure, as well as final customers of the petroleum products. All players are modeled as profit-maximizing players considering the actions taken by the other players, assuming perfect and complete information as well as foresight. This yields a Nash equilibrium model. We take into account infrastructure constraints such as production and refining capacities, global reserves and trade routes. See Figure 2 for an illustration of the different players and fuels at each node.

Prices as well as investments in infrastructure, production and refining quantities 


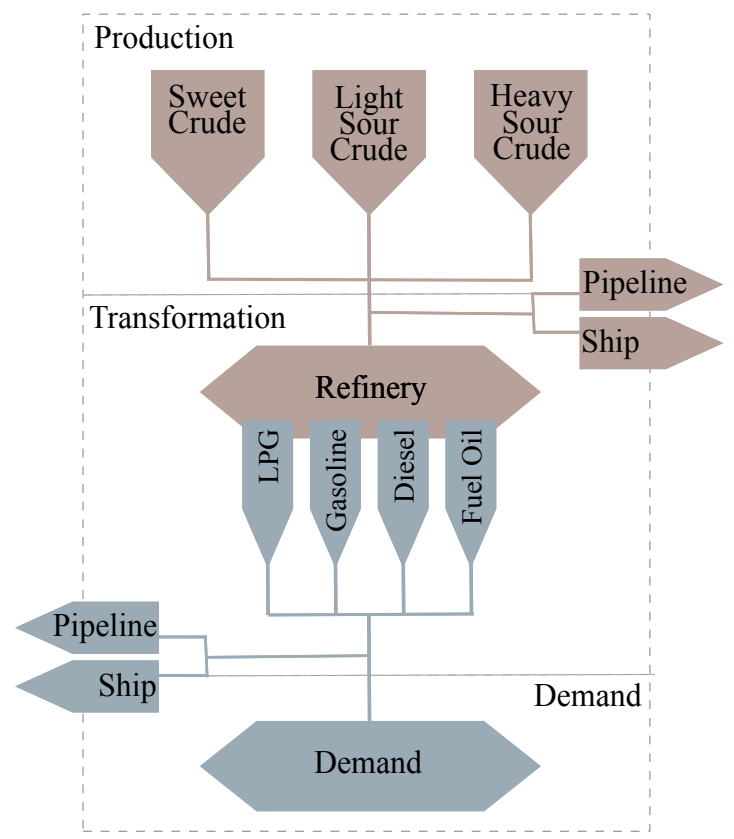

Figure 2: Players in the model of one representative node connected to other countries (with the same layout) via pipeline and shipping routes

are endogenous to the respective player's optimization problem. The players decide whether to invest or not, as well as how much to produce depending on the decisions taken by the other players and the resulting market prices. In addition, the model can assign different levels of market power to specific players. Strategic behavior is especially important in the global crude oil market as the high share in reserves of some players prevents perfect competition. In the given scenario, we implemented market power for individual OPEC members as well as Russia, to do so we used a conjectural variations $(\mathrm{CV})$ formulation. For a more detailed discussion of market power in the crude oil market and the validity - as well as the limitations of this approach - we refer to Huppmann (2013) and Huppmann and Holz (2012).

In order to tackle the research question at hand with a more detailed emphasis on the global crude oil and petroleum product sector, the energy-system aspects of $\mathrm{Mul}$ tiMod beyond oil were omitted. The data set used by Huppmann and Egging (2014) in MultiMod includes all fossil and renewable energy carriers and multiple demand sectors, allowing to analyze substitution effects along the supply chain. Instead, we implemented an extended and disaggregated representation of the oil supply chain, considering an in-depth approach to the given crude oil qualities and oil products, as well as transformation technologies. Hereby, three oil qualities were implemented in the model: sweet crude, light sour crude and medium/heavy sour crude. In addition, the model includes four oil product categories with rising distillation temperature: LPG, gasoline, diesel (including light fuel oil), and heavy fuel oil. Gasoline and diesel are the high-demand, high-value products, while LPG only has a comparable small share of the total oil product demand. Heavy fuel oil has a very limited demand, can even be categorized as a residual product of the refineries. It is also the most environmentally damaging oil product. As a consequence, refineries seek to reduce their output of heavy fuel oil, since it trades at a discount compared to the crude oil before refining. 
To represent the refinery sector, the model includes a set of four refinery configurations with an increasing level of complexity: hydroskimming, catalytic cracking, hydrocracking and coking. The refinery configurations are chosen in line with Abella and Bergerson (2012a) and are also used by the Carnegie Endowment for International Peace in their Oil Climate Index (2015). Abella and Bergerson (2012b) also discuss in more depth the technical structure of the refinery configurations and the used technical units, as well as the flows across the different entities in the refining process. All crude oils can, in principle, be transformed in all refinery configurations. Sweet crude has the highest competitive advantage due to its better yields for more valuable products, especially in hydroskimming refineries. Hydroskimming refineries are the conventional technology mainly used for sweet crude. For the transformation of heavy crude, more complex refineries are needed to obtain a substantial share of valuable products. Coking refineries are the ones most suited for heavy crude oil, as they are the only refinery configuration reducing the low-value fuel oil output of heavy crude to a low level of $4 \%$. Catalytic cracking refineries yield more gasoline, whereas hydrocracking refineries have a higher diesel output, but still yield $16 \%$ fuel oil for heavy crude oils (see Table 1 for an overview). Through the transformation yields, the availability of a certain crude oil influences the strategic investments of the refinery sector.

Crude oil production and oil product consumption data in the base year 2010 is taken from the IEA "World Extended Energy Balances" (2014). Reference values for the demand projections are derived from the European Commission's "EU energy trends to 2050" (2013) for the European nodes, and from the IEA "World Energy Outlook - New Policies Scenario" (2013) for the rest of the world. As the stated crude oil production figures are not separated by crude quality, a crude slate for each region was determined using data from ENI (2014) and IEA (2012). The refinery setup, including the product yields and the configuration capacities per node for the base year, are obtained from IEA (2012) and the Oil \& Gas Journal (2010). See Table 2 for a more detailed overview on the data used to parametrize the crude oil infrastructure capacities and costs.

\section{The United States refinery market and the global trade flows of crude and products}

In the following discussion, we focus on the induced changes in the US refinery market, as well as global flows from and to the United States, following the lift of the US crude oil export ban. There are two opposite drivers of the global oil agenda in the next decades; on the one hand, the OECD-countries will experience decreasing demand over the next decades, while refinery capacity is plentiful; on the other hand, developing countries will see strongly rising demand, while available refining capacity is still low and mostly comprised of conventional transformation technology. The changes of advanced refinery capacity in some key regions in our model are illustrated in Figure 3 In the following, the scenario results of lifting the United States crude ban are compared to the base case, in which crude exports remain prohibited.

\subsection{Crude oil and oil product trade in the United States}

Figure 4 indicating the US net imports, illustrates the rise in sweet crude exports from the United States in 2020 and 2030, when the crude ban is lifted. These exports are mainly destined for South America (39\%) and Asia (38\%). At the same time, diesel exports from the United States decline by $61 \%$ compared to the base case. The exports recover to some extent in 2030, when diesel is mainly sent to the Middle East and South America. By then, the former main importer Europe faces significant de- 


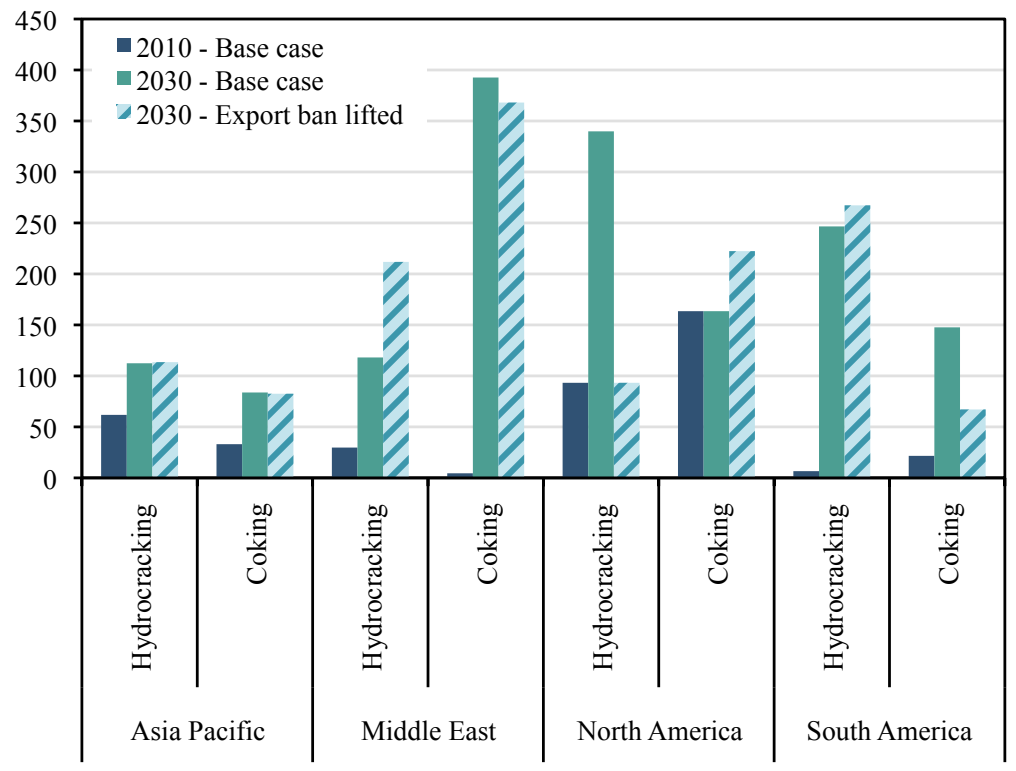

Figure 3: Changes in advanced refinery capacity in selected regions (in mtoe)

mand reductions due to the effects from policy interventions towards increased energy efficiency and the electrification of the transportation sector. Gasoline exports from the US are approximately equivalent in both scenarios. See Figure 6 for an illustration on how the global flows for crude oil in 2030 change, when the crude ban is lifted.

In 2020, the United States refinery activities decrease compared to the base case because of investments in advanced refinery capacity in other regions (see Figure 3); the US regains market share to some extent in 2030 due to increased global demand (see also Figure 5). In addition, in the case of lifting the US export ban, the share of sweet crude transformed domestically is reduced to almost zero in 2020 and 2030, whereas the amount of heavy crude oil refined increases, with the advanced, high-tech refineries in the US being well suited to process these types of crude oils. In 2020, the import volume of heavy crude rises by $12 \%$, while the main supply source shifts from Canada to South America. In 2030, heavy crude imports are almost four times as high as 2020, as refinery activities ramp up again (see Figure 4); main sources are the Middle East (37\%), Russia (34\%) and South America (29\%).

On the product side, the United States depend more on product imports once the crude ban is lifted compared to the base case, even though the effect is less drastic due to the refinery ramp-up in 2030. This is driven by the export of high-yield sweet crude in addition to reduced refinery investments in the scenario case. A more detailed evaluation of the adaptations in the US refinery sector will follow in the next section. Diesel suppliers in 2020 include Canada (27\%) and, as a new source in the scenario case, South America (29\%). In 2030, diesel is mainly sourced from within North America (79\%), see also Figure 6 for a comparison. Gasoline is imported from South America (44\%) in 2020 and in 2030 from South America (23\%), Canada (27\%) and Turkey $(20 \%)$.

Figure 7 shows the gross imports and exports of crude oil and oil products. Imports and exports of crude as well as of oil products increase once the export ban is lifted. As imports and exports rise in lockstep, the gap between imports and exports is virtually identical between the two scenarios, and is decreasing over the years in both scenarios. 


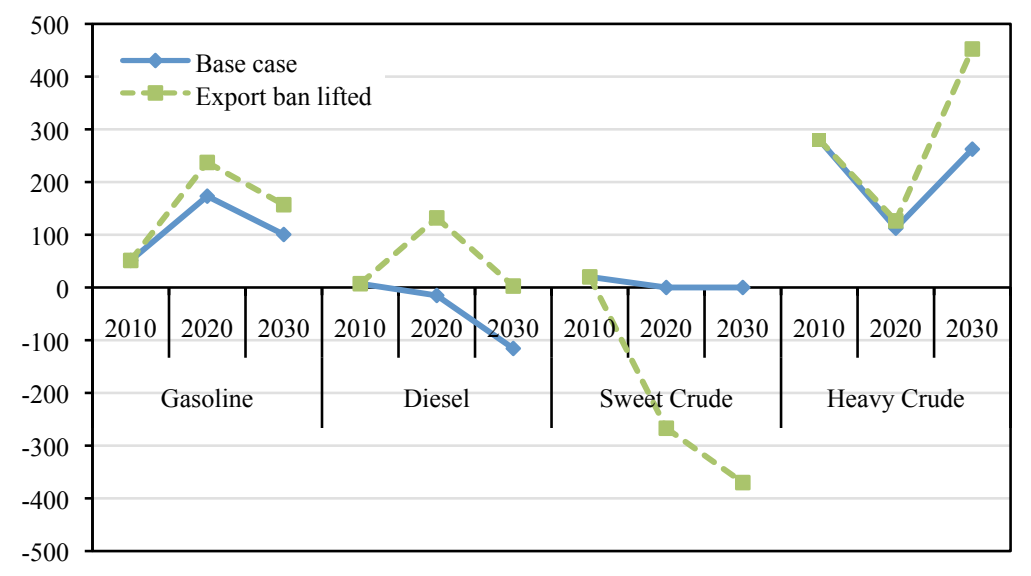

Figure 4: Net import projections for the United States in the base and scenario case (in mtoe)

The United States imports exceed the exports even with the crude ban lifted. This way, the United States will continue to be vulnerable to global price shocks.

\subsection{Adjustments in the US refinery sector}

The trade adaptations have great influence on the investment behavior of the United States refinery sector. Figure-5illustrates the volumes transformed in the given refinery configurations. As the hydrocracking and coking refineries are utilized at full capacity in both scenarios, the graph also indicates the capacity investments available from 2020 in the base case. With the export ban remaining in place, the United States massively expand hydrocracking capacity. With the crude ban lifted, these investments are canceled, since the refinery was used solely to transform sweet crude oil, which is now exported instead. Refinery activity is generally reduced in the scenario case, and in 2030 partly replaced by lower-yield hydroskimming and Catalytic Cracking refineries. The imported heavy crude fully utilizes the refinery capacities of the coking, hydrocracking and hydroskimming refineries in 2030, whereas the catalytic cracking refineries process mainly imported light sour crude. According to our numerical results, no refinery investments are economically viable in the United States once the crude ban is lifted.

In Figure 8 the average prices of a ton of oil equivalent for some major crude oils and oil products in the United States are illustrated; one ton of oil equivalent contains about 7 barrel. The colored bars mark the base case, the shaded bars indicate the prices under the assumption that the crude ban is lifted (scenario case). There is almost no difference between the two scenarios; this confirms the discussion by Kilian (2015) and Medlock (2015) on the limitations of the impact of a lift of the export ban on the United States industry and final consumers. Diesel fuel is only $1 \%$ more expensive when lifting the export ban while heavy fuel is $1 \%$ cheaper, so the differences are negligible. Due to the strong competition on the global crude oil markets, only the global flows and the strategic adjustments of the refinery sector change comparing the two scenarios.

According to our numerical results, in future periods sweet crude oil is traded at a higher price than gasoline in either scenario. This is due to the slow-down in global demand for gasoline as well as the rise in demand for sweet crude because of its transformation advantages considering the large global share of conventional refineries 


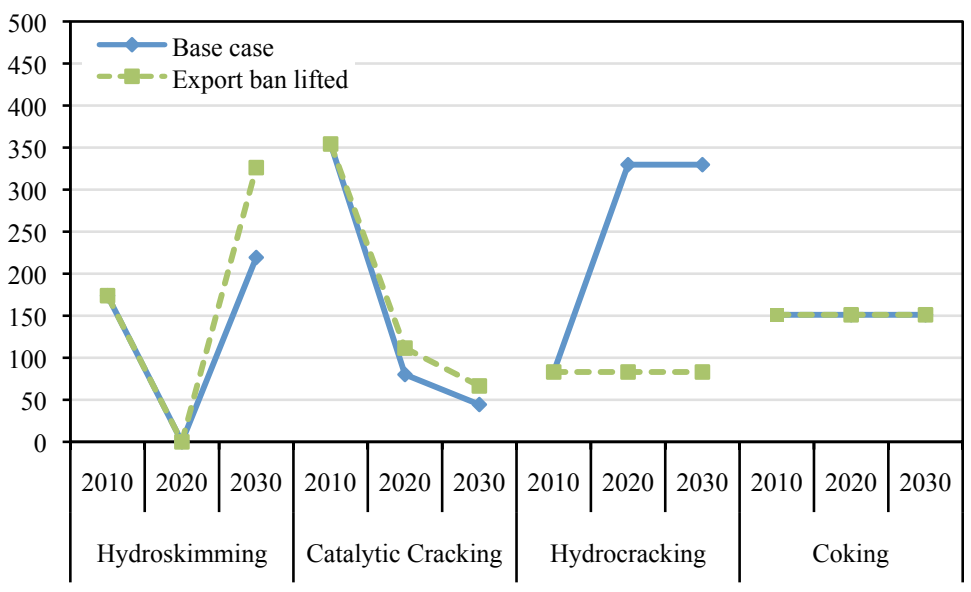

Figure 5: Refinery configurations used in the United States in the base and scenario case (in mtoe)

remaining. The advanced refinery sector therefore generates competitive advantages for the US oil sector by transforming the cheaper heavy crude oils, allowing for the higher-value sweet crude to be exported. The steadily rising demand for diesel fuels drives the global refinery adaptions and market prices.

Even though the prices are approximately the same, refiners in the US lose in the given scenario relative to the crude export-ban remaining in place. The crack spread per output unit decreases by $11 \%$ from $119 \$$ to $106 \$$ per ton of oil equivalent in 2020 and by $46 \%$ from $122 \$$ to $66 \$$ in 2030 . That is because of the changed crude quality input and the reduced output quantities due to the less efficient yields of heavy crude. The high-yield sweet crude is now being exported and the heavy crude is transformed instead. As heavy crude has a far worse yield than sweet crude especially in conventional refineries, more crude oil is needed to produce the same amount of oil products. The cheaper price of heavy crude does not fully compensate for this effect. The stated crack spread does not only consider the price arbitrage between crude and products but also the costs of refining in the different refining configurations.

\subsection{Global implications}

The importers of US sweet crude - foremost South America and Asia - benefit as they are able to increase their product output while at the same time requiring less investments in advanced refining technology or upgrading of existing capacity. They can utilize their conventional refineries at higher rates and export their surplus heavy crude to the United States or Asia (see Figure 6). The United States export their high-value sweet crude instead of refining it domestically. In return, they transform more heavy crude imported from South America, Russia and the Middle East. They are able to handle the adjustment without further investments because they already possess a large share of advanced refineries. Due to the increased crude exports from North and South America to Asia, Africa and the Middle East have to adjust their flows (see Figure 6).

On the product side, especially the trade within the North American region increases. The United States reduce their exports of diesel to the Middle East. At the same time, the diesel exports from the Middle East to Asia increase in the scenario case. This indicates further investments in diesel-focused refineries in the Middle East. Thus, the Middle East suppliers lose some market share in crude imports to Asia, but 


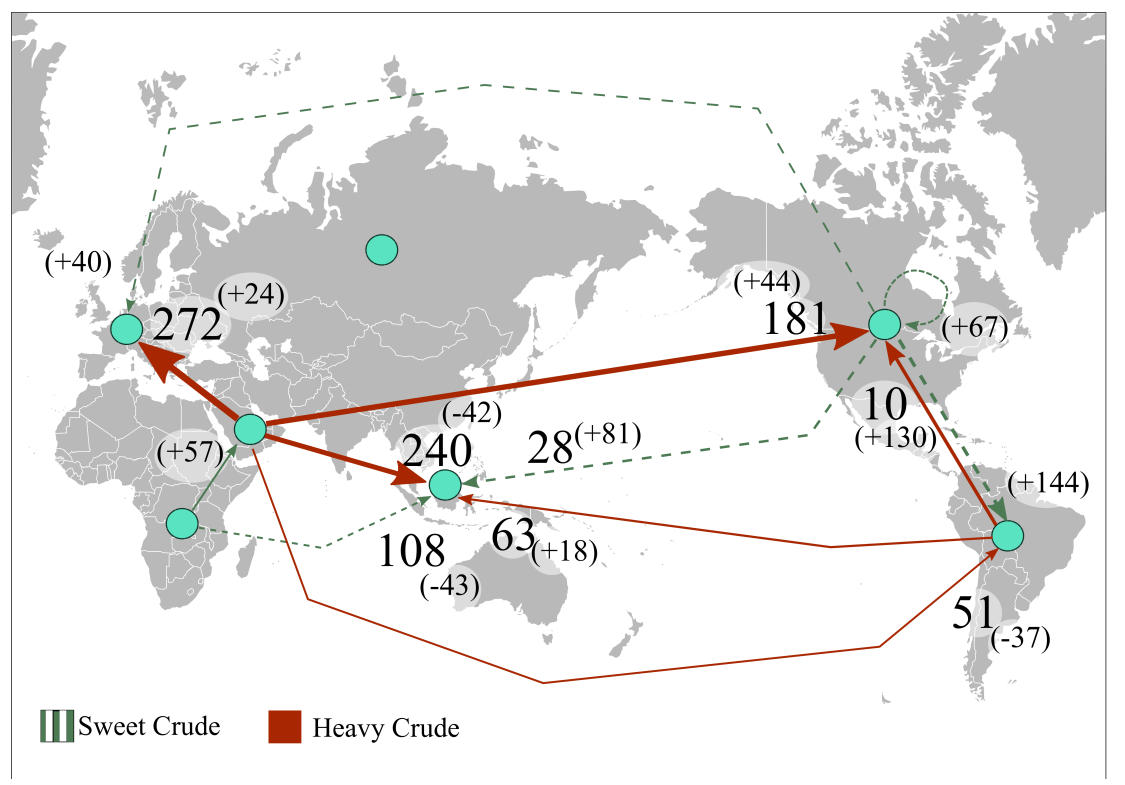

Figure 6: Changes of global flows for crude oil comparing the base to the scenario case (change in brackets) in 2030 in aggregated regions (in mtoe)

take up a higher share of product imports due to advanced refinery investments. So, lifting the crude export ban and supplying more sweet crude to the market, reinforces the trend of the Middle East turning from a crude oil exporter to a key player in the oil product market. This way, they climb up the value chain and earn higher profits in comparison to exporting unrefined crude oil.

\section{Conclusions and policy implications}

We analyze the impacts of lifting the US crude export ban on the North American and international crude oil and petroleum product trade. The ban was established as a response to the first oil crisis and the strategic price-setting by OPEC, aiming to insulate domestic consumers against price shocks in the global oil market. Because the United States are still importing roughly half of their domestic consumption, US prices are nevertheless highly dependent on developments in the global market. At the same time, the ban arguably has exacerbated domestic infrastructure bottlenecks and has prevented the most economically beneficial allocation of different crude oil types to the refineries that are best suited to handle them and where the crude oils would yield the highest spark spread. The export ban of non-processed crude oil also induces substantial trade of (non-banned) oil products leading to investments in advanced refining capacity resulting in lower utilization of conventional US refineries. Thus, the ban causes an inefficient resource allocation in the refining sector, both domestically and globally, when taking into account the high share of fixed costs in the industry.

According to the numerical scenario results, lifting the United States crude ban would only have limited influence on US customers, as fuel prices change only marginally. Domestic producers, however, gain from the crude exports as they are able to sell their crude at global market prices instead of prices distorted by local bottlenecks. They export their domestic sweet crude from shale oil plays, which was formerly "trapped" 
at Cushing because of missing transport infrastructure to refineries at the East Coast. Over the next decades, this high-yield sweet crude gains even more importance in the oil market, as it is compatible with the large global share of conventional refineries. In contrast to heavy sour crude oils, it yields high shares of the oil products where demand is projected to grow due to increasing transportation demand in China and the developing countries.

The United States benefit from their large capacity of advanced refineries and their ability to transform heavy sour crude oils, which are traded at a discount on the global market. In doing so, through their increased imports and exports, they increase their interdependence with the global oil market. The main goal of the crude ban was to insulate the United States market against volatility of global oil markets - but it stands to reason that this goal is unattainable anyway in today's integrated markets. The United States never were independent of the global oil market, due to their domestic demand by far exceeding their own production volume. Even if the shale oil boom would change that situation in the medium term, this would still require vast investments in infrastructure to transport the different crude qualities to the areas with suitable refinery technology and sufficient capacity. Given the uncertainties of the market - as evidenced by the dramatic price drop over the past two years - these investments are unlikely. Lifting the crude ban would also imply investments in export infrastructure - but at the same time, decisive change of legislation decreases this uncertainty for the crude oil industry, making the investments more likely. Leaving the situation in limbo, with exceptions and a case-by-case litigation of exports, would mean forgoing a large share of profit for US producers and wasting a lot of global market potential for sweet crude.

The global markets gain from the additional source of high-value crude oil once the crude ban is lifted. Mainly South America, Asia, Europe and Mexico substitute some of their heavy crude transformation of the base case with imported sweet crude in the scenario case. The additional source of crude from the American continent also incentivises the Middle East to invest even more in advanced refinery capacity. Transforming that region from a crude to a product exporter, it exports a higher share of oil products to the strongly growing Asian markets and climbs up the crude oil value chain. The United States itself soaks up more of the global heavy crude supply, using its already installed advanced refineries more efficiently. We therefore conclude that lifting the US export ban is the right policy decision, both for the US crude oil industry and consumers as well as for global players. Ending the ban will allow a more efficient utilization of refineries, give rise to a more beneficial trade of different crude and product types, and remove a significant distortion of the current global crude oil market.

\section{Acknowledgments}

This work was carried out during a research visit by Lissy Langer at the Civil Engineering Department \& Systems Institute of the Johns Hopkins University, financed by the DAAD PROMOS grant awarded by the TU Berlin. We are grateful to Sauleh Siddiqui for hosting Ms. Langer during her research visit, and we thank him, David Livingston, Olufolajimi Oke, Benjamin Boldt and the participants at the Young Energy Economists and Engineers Seminar (Madrid, November 2015) for many valuable comments and discussions. 


\section{$7 \quad$ References}

Abella, J., Bergerson, J., 2012a. Model to investigate energy and greenhouse gas emissions implications of refining petroleum: Impacts of crude quality and refinery configuration. Environmental Science and Technology 46 (24), 13037-13047.

Abella, J., Bergerson, J., 2012b. Model to investigate energy and greenhouse gas emissions implications of refining petroleum: Impacts of crude quality and refinery configuration. Supporting Literature.

Aguilera, R. F., 2014. Production costs of global conventional and unconventional petroleum. Energy Policy 64, 134-140.

Aguilera, R. F., Eggert, R. G., Lagos CC, G., Tilton, J. E., 2009. Depletion and the future availability of petroleum resources. The Energy Journal 30 (1), 141-174.

API, 2014. Understanding crude oil and product markets. American Petroleum Institute. industry report.

Avis, M., Birch, C., 2009. Impacts on the EU refining industry \& markets of IMO specification changes \& other measures to reduce the sulphur content of certain fuels. Purvin\&Gertz Inc. Prepared for: European Commission DG Environment.

Benoit, B., Zurlo, J., 2014. Overcoming the challenges of tight/ shale oil refining. Petroleum Technology Quarterly, 37-44.

Borenstein, S., Kellogg, R., et al., 2014. The incidence of an oil glut: Who benefits from cheap crude oil in the midwest? Energy Journal 35 (1), 15-33.

BP, 2014. Statistical review of world energy.

Brown, S., Huntington, H., 2015. Evaluating US oil security and import reliance. Energy Policy 79, 9-22.

CEIP, 2015. Oil Climate Index. http://oci.carnegieendowment.org/ [Accessed: 2015-04-22], Carnegie Endowment for International Peace.

EIA, 2015a. Effects of removing restrictions on US crude oil exports.

EIA, 2015b. US crude oil product to 2025: Update projection of crude types.

ENI, 2014. World oil and gas review. Industry report.

European Commission, 2013. EU energy trends to 2050, Update 2013.

Ferris, M., Munson, T., 2000. Complementarity problems in GAMS and the PATH solver. Journal of Economic Dynamics and Control 24 (2), 165-188.

Grossman, P., 2013. US energy policy and the pursuit of failure. Cambridge University Press.

Hackett, D., Noda, L., Grissom, S., Moore, M., Winter, J., 2013. Pacific basin heavy oil refining capacity. SPP Research Paper 6 (8).

Huppmann, D., 2013. Endogenous shifts in OPEC market power: A Stackelberg oligopoly with fringe. DIW Discussion Paper no. 1313. 
Huppmann, D., Egging, R., 2014. Market power, fuel substitution and infrastructureA large-scale equilibrium model of global energy markets. Energy 75, 483-500.

Huppmann, D., Holz, F., 2012. Crude oil market power- a shift in recent years? The Energy Journal 33 (4), 1-22.

IEA, 2012. Refinery margins - Methodology notes. International Energy Agency.

IEA, 2013. World Energy Outlook 2013. International Energy Agency.

IEA, 2014. Extended world energy balances. International Energy Agency.

Kilian, L., 2015. The impact of the shale oil revolution on US oil and gasoline prices. CFS Working Paper.

Lantz, F., Gruson, J., Saint-Antonin, V., 2005. Development of a model of the world refining for the POLES model: the OURSE model. IFP report for the JCR-Sevilla 58,808 .

Lantz, F., Saint-Antonin, V., Gruson, J., Suwala, W., 2012. The OURSE model: Simulating the world refining sector to 2030. European Commission Joint Research Centre, IPTS report 25221 EN.

Medlock, K., 2015. To lift or not to lift? - the US crude oil export ban: implications for price and energy security. Rice University's Baker Institute for Public Policy Study Report.

Oil \& Gas Journal, 2010. Worldwide refineries - Capacities as of Jan. 1, 2011. Oil \& Gas Journal.

Oil \& Gas Journal, 2011. World production 2010. Oil \& Gas Journal.

Oke, O., Huppmann, D., Marshall, M., Poulton, R., Siddiqui, S., 2016. Transport infrastructure and the crude-by-rail problem: an equilibrium model of the North American oil market. mimeo.

Platts, 2013. New crudes, new markets. Industry report.

Purvin \& Gertz Inc., 2008. Study on oil refining and oil markets. Industry report.

Purvin \& Gertz Inc, 2009. Overview of the European downstream oil industry. http:// Www.petder.org.tr/uploads/2013/05/74b16d2b2dc94da1c932a12399d59593.pdf [Accessed: 2015-09-04].

Richter, P., 2015. From boom to bust? A critical look at US shale gas projections. Economics of Energy \& Environmental Policy 4 (1).

Smith, J., 2015. Valuing barrels of oil equivalent. The Energy Journal 36 (Adelman Special Issue), 179-194.

Verleger Jr., P., 2015. Structure matters: Oil markets enter the adelman era. The Energy Journal 36 (Adelman Special Issue), 129-157.

Wauquier, J., Favennec, J., Trambouze, P., Baker, R., 2001. Petroleum refining: Refinery operation and management. Editions TECHNIP, France. 


\section{Additional Figures and Tables}
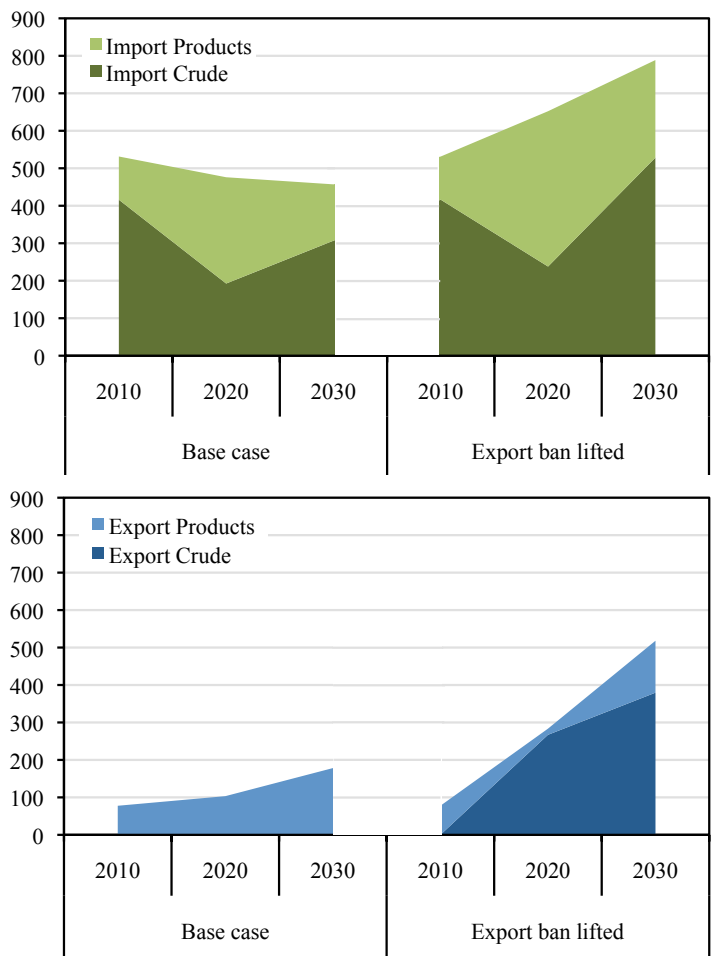

Figure 7: Gross imports and exports of crude oil and oil products in the United States (in mtoe) 


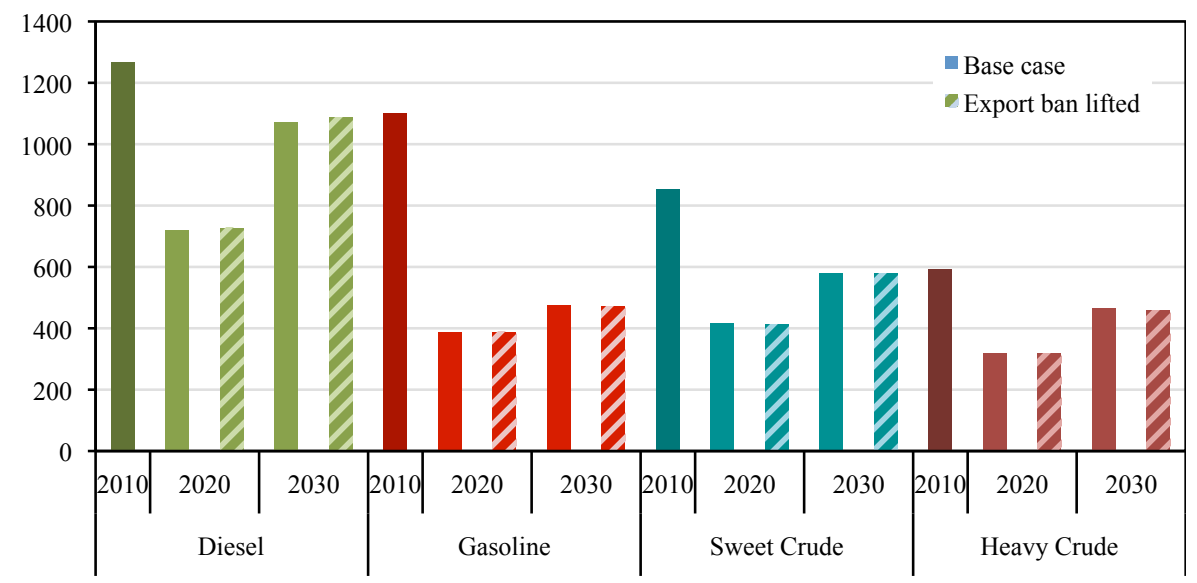

Figure 8: Average prices of selected crude oils and oil products in the United States (in $\$$ per toe)

\begin{tabular}{|c|c|}
\hline Crude oil slates & ENI (2014); Oil \& Gas Journal (2011) \\
\hline & Lantz et al. $(2012,2005)$ \\
\hline & Purvin \& Gertz Inc. $(2008) ;$ EIA $(2015 b)$ \\
\hline Oil production (2010) & IEA (2014) \\
\hline Oil product demand (2010) & IEA (2014); BP (2014) \\
\hline Demand projections (global) & IEA (2013) \\
\hline Demand projections (EU) & European Commission (2013) \\
\hline Refinery capacities (2010) & Oil \& Gas Journal $(2010)$ \\
\hline Refinery product yields & IEA $(2012)$ \\
\hline Refinery GHG emissions & Abella and Bergerson (2012a); CEIP (2015) \\
\hline Refinery operational costs & Purvin \& Gertz Inc. (2008); IEA (2012) \\
\hline Refinery investment costs & Wauquier et al. (2001); Purvin \& Gertz Inc (2009) \\
\hline & \\
\hline
\end{tabular}

Table 2: Data added to derive a crude oil infrastructure 